\title{
O ISEB, \\ Nelson Werneck Sodré \\ e a culturabrasileira: \\ um testemunho histórico
}

\author{
Olga Sodré*
}

O trabalho narra a participação do historiador Nelson Werneck Sodré em uma das mais polêmicas e controvertidas instituições brasileiras de ensino, dos anos cinquenta/sessenta, o Instituto Superior de Estudos Brasileiros, que ficou famoso pela sigla ISEB. Delineia não apenas os antecedentes do ISEB e os principais acontecimentos da vida dessa instituição, mas também seu papel e sua importância na luta pelo desenvolvimento e por uma cultura nacional, popular e democrática, o sentido e a atualidade dessa experiência para a história do Brasil e o momento presente de nosso país.

Palavras-Chave: História, Cultura, Memória

The article narrates the participation of historian Nelson Werneck Sodré in one of the most contentious and controversial Brazilian educational institutions, from the years fifties and sixties, the Instituto Superior de Estudos Brasileiros, made famous by ISEB. Outlines not only the background of the ISEB and the main events of the life of this institution, but

\section{Os antecedentes do ISEB}

A sigla ISEB é o símbolo de uma experiência história que nos ajuda a entender o passado e o presente do Brasil. O Instituto Superior de Estudos Brasileiros - Nelson Werneck Sodré (ISEB-NWS), criado no Rio de Janeiro, em 2008, para preservar a memória e a obra desse grande historiador brasileiro foi inspirado no nome de um centro de estudos no qual ele ensinou, pesquisou e produziu sua obra de maturidade, entre 1954 e 1964, e que tornou célebre a sigla ISEB. Essa instituição de ensino e pesquisa foi instituída em 1955, um ano após o suicídio

\footnotetext{
* Doutora em Filosofia, em Psicologia Clínica e pós-doutorado em Filosofia. olgasodre@gmail. com
} 
also its role and its importance in the struggle for development and for a national, popular and democratic culture, the sense and the ac- tuality of that experience for the history of Brazil and the present of our country.

Key words: History, Culture, Memory.

do Presidente Vargas, pelo seu vice-presidente e sucessor interino, Café Filho ${ }^{1}$, como um órgão vinculado ao Ministério da Educação e Cultura. Suas raízes foram plantadas durante o governo de Vargas, tendo sido elaborado com base em um projeto do professor Alberto Torres ${ }^{2}$. Apesar da conotação autoritária e antiliberal do pensamento desse pesquisador social, criticada pelo professor de sociologia do ISEB, Guerreiro Ramos, esse pensador desenvolveu idéias interessantes sobre a identidade nacional e sua base na cultura e na ação das elites intelectuais, delineando o papel que a elas deveria ser dado pelos governos, o que foi realizado posteriormente, na época de Vargas, como é narrado por Nelson Werneck Sodré, em seu livro Luta pela Cultura ${ }^{3}$.

Foi um grupo de intelectuais desse governo, que ficou conhecido como o Grupo Itatiaia ${ }^{4}$, que esboçou o projeto do ISEB, ainda no governo do presidente

${ }^{1}$ Pelo Decreto n. 37.608, de 14 de julho 1955.

${ }^{2}$ Alberto Torres (1865 - 1917) foi um político, jornalista, bacharel em direito, e pensador social brasileiro preocupado com questões da unidade nacional e da organização social brasileira. Assim como a identidade nacional, a cultura brasileira, para ele, é coisa que não existia ainda. Faltaria uma elite intelectual indispensável à condução dos destinos nacionais e à formação de um caráter nacional, em função da inconsciência mental na qual o país ainda vivia. Caberia aos intelectuais, então, construir o conhecimento que tornaria possível a criação de uma consciência nacional, atuando sob a égide estatal. Essa missão seria urgente, na medida em que toda nacionalidade é moldada à imagem e semelhança de suas elites. A. Torres indica, por conseguinte, a existência de dois caminhos a serem percorridos: a consolidação da independência social e econômica a partir da preservação do que ele chama de órgãos vitais da nacionalidade, ou a transformação do país em uma colônia tropical de companhias e sindicatos estrangeiros A opção a ser feita seria, então, entre nacionalismo e alienação. O conceito de alienação é o eixo de seu nacionalismo. Uma nação alienada é uma nação que ainda não tomou consciência de seus reais interesses e, por isto, permanece ainda - mesmo que seja formalmente independente - na condição de colônia. Elites desligadas da realidade nacional, alheias aos problemas nacionais e despreocupadas no que tange a seu estudo, são elites alienadas.

${ }^{3}$ SODRÉ, Nelson Werneck. A luta pela cultura. Rio de Janeiro: Editora Bertrand Brasil, 1990.

${ }^{4}$ Eram assim chamados porque, quando Vargas era ainda vivo, seus elementos haviam passado alguns dias na sede do Parque Nacional de Itatiaia, por concessão do Ministro da Agricultura, ali discutindo os problemas nacionais. 
Getúlio Vargas, mas este projeto só seria, entretanto, implantado nos governos seguintes. O Grupo Itatiaia, que reunia intelectuais do Estado do Rio de Janeiro e de São Paulo, era liderado pelo professor Hélio Jaguaribe. Antes da criação do ISEB, esse professor articulou uma instituição denominada Instituto Brasileiro de Economia, Sociologia e Política (IBESP). Esse grupo de estudos foi criado, em 1952, a partir dos debates sobre a questão do petróleo e dos rumos do desenvolvimento nacional. Era um grupo forte pelas funções exercidas por alguns de seus componentes e pela assessoria que forneciam ao governo, e seus intelectuais começavam já, no início da década de cinquenta, a ocuparem um lugar no espaço político. Grande parte de seus membros girava em torno do governo Vargas e quase todos eram funcionários. Isso indica que o ISEB surge relacionado à abertura de um espaço de debate público, no qual os intelectuais passaram a ter um papel político e cultural fundamental.

O primeiro contato de Nelson Werneck Sodré com o IBESP ocorreu, no primeiro trimestre de 1954, por intermédio do professor Guerreiro Ramos, que o convidou a integrar esse grupo e participar de suas atividades. Esta instituição foi responsável pela edição da Revista Cadernos de Nosso Tempo, editada entre 1953 a 1956 e em torno da qual viria a se constituir o núcleo do futuro ISEB. No primeiro trimestre de 1954, quando passávamos as férias, no Rio, como fazíamos todos os anos, desde que meu pai fora 'exilado' na fronteira do Rio Grande do Sul, ele conheceu o professor Guerreiro Ramos, que já lecionava na EBAP (FGV), aonde eu viria a estudar de 1960 a 1964, ano em que me formei como bacharel em administração pública. Esse professor logo o convidou a participar desse grupo e a escrever trabalhos para essa revista, onde publicou seu estudo sobre o desenvolvimento das classes sociais no Brasil, assim comentado por esse professor, em carta a ele endereçada em 31 de maio de 1954:

"Meu caro Sodré, Acuso recebimento dos recortes de jornais e de suas conferências, que estão magistrais. As ditas conferências constituem um dos pontos altos do Seminário que, aliás, está despertando um interesse extraordinário. Você imagine que temos mantido o salão do Ministério da Educação quase lotado. $\mathrm{O}$ interesse dos militares pelo empreendimento tem sido notável. Fizeram-se representar enviando oficiais, entre outros, órgãos do Estado Maior das Forças Armadas, da Escola Superior de Guerra e do Departamento Técnico do Exército, Oficiais da Marinha também estão presentes e é na Marinha que se imprimem as 
conferências, gente do Itamarati, inclusive um ministro de assuntos econômicos. Posso lhe dizer que o seminário é um sucesso, até agora." 5

A correspondência entre esses dois representantes do grupo de fundadores do ISEB se prossegue até o retorno definitivo de Nelson Werneck Sodré, ao Rio, e por ela já se nota que esse historiador era considerado um elemento de contato com os elementos nacionalistas do Exército aos quais estava ligado. O suicídio do Presidente Vargas, em 24/8/1954, alastra um estopim de pólvora por todo país, freando a tentativa dos conspiradores dentro do governo de realizar um golpe político e obrigando-os a caminhar rumo a um processo eleitoral para a escolha do novo presidente. As forças democráticas se aglutinam, então, em torno da candidatura de Juscelino Kubitschek. Em abril de 1955, quando chega ao Rio para servir no Estado Maior do general nacionalista Newton Estillac Leal, este veio a falecer subitamente e Nelson Werneck Sodré teve que, de público e diante das mais altas testemunhas ${ }^{6}$, tomar partido nessa luta que foi dura e se agravou ao longo de todo o período dos anos cinquenta/ sessenta até culminar no golpe de 1964 e na implantação da ditadura militar.

É importante observar que, em 1955, as forças políticas e militares já estavam divididas entre aqueles que, tendo o general Lott ${ }^{7}$ à frente, defendiam a ordem legal e os que conspiravam contra ela. Ainda em novembro de 1955, o grupo de conspiradores articulou um golpe militar para evitar a posse de Juscelino Kubitschek, após ter este obtido a maior votação no pleito de 3 de outubro de 1955. Nelson Werneck Sodré, então na Diretoria Cultural do Clube Militar, participou ativamente da defesa da ordem legal junto com o grupo de militares nacionalistas, liderado pelo General Lott, que tinha sido mantido no cargo de Ministro da Guerra. A ação política desses militares foi decisiva para que o re-

${ }^{5}$ SODRÉ, Nelson Werneck. Op. Cit., p. 128.

${ }^{6}$ Alguns dias apenas após sua chegada, ele já enfrentava o delicado problema de pronunciar, no túmulo desse general nacionalista, as palavras de despedida de seus companheiros. Sabendo do fato de uma conspiração já montada, mantida e desenvolvida dentro do governo, tinha Nelson Werneck Sodré que enfrentar a tarefa de fazer a defesa da ordem legal, na presença das duas figuras militares que se opunham em torno dessa questão: a do ministro do Exército - da Guerra, dizia-se então general Henrique Batista Duffles Teixeira Lott e a do ministro da Aeronáutica, brigadeiro Eduardo Gomes. O primeiro coordenava com dificuldades as forças de defesa da ordem legal, enquanto o segundo conspirava contra ela.

${ }^{7}$ Em 1954, quando o vice-presidente João Café Filho tomou posse na presidência da República, no dia do suicídio do Presidente Vargas, ele escolheu o general Lott para ocupar o Ministério da Guerra. 
sultado da eleição fosse cumprido e os eleitos pelo voto popular assumissem a Presidência da República ${ }^{8}$. Só quem viveu e acompanhou de perto esse processo de luta pelo desenvolvimento brasileiro sabe como foram difíceis os embates dos grupos em conflito e como eles atingiram duramente aqueles que defendiam os interesses populares e nacionalistas, como Nelson Werneck Sodré, em sucessivas conspirações e tentativas de bloquear a ordem legal e impedir a ascensão das forças nacionalistas e populares, que culminaram com o golpe de $1964^{9}$.

\section{As Iutas politicas e culturais e à formação do ISEB}

O ISEB foi, portanto, criado num período de aguçamento das contradições e lutas políticas, como se pode verificar pela narração de Nelson Werneck Sodré, em seu livro A Luta pela Cultura. Nesse livro, ele se espanta diante do fato de o grupo do IBESP, que era tão ligado ao governo Vargas, ter subsistido no governo de Café Filho, que o sucedera e era o seu antípoda, sendo controlado por um grupo militar especializado em golpes de estado. O grupo do IBESP conseguiu inclusive que esse Presidente da República interino, criasse o ISEB, mas, nosso historiador não pode explicar esse fato, pois ainda não estava entrosado ao grupo, embora conhecesse suas figuras principais. Assim sendo, os primeiros

\footnotetext{
${ }^{8} \mathrm{O}$ movimento golpista continuou, entretanto, vivo e atuante contra essa defesa da ordem e da legalidade feita pelos militares nacionalistas, encabeçada pelo general Lott, que desagradava profundamente aos círculos oposicionistas do governo Kubitschek. Os militares nacionalistas, entre eles o general Lott e Nelson Werneck Sodré, tiveram ainda que enfrentar pesados ataques da imprensa oposicionista, como é relatado por Nelson Werneck Sodré em vários de seus livros, em particular em Luta pela Cultura.

${ }_{9}$ O general Lott, por exemplo, foi extremamente combatido por se ter declarado favorável ao projeto de lei que instituía o voto aos analfabetos, que foi derrotado na Câmara em agosto de 1957. Outro exemplo importante foi o da luta pela Petrobrás, veementemente defendida pelos militares nacionalistas. Em função dessa luta, foi criada em 1956 a Frente Parlamentar Nacionalista, na Câmara dos Deputados, que reuniu parlamentares de quase todos os partidos políticos em defesa de ideais nacionalistas e lançou a candidatura do general Lott à presidência da República nas eleições de 1960, da qual participou intelectualmente Nelson Werneck Sodré. O general Lott perdeu a eleição e Jânio Quadros tomou posse no dia 31 de janeiro de 1961, mas renunciou a seu mandato na presidência da República em 25 de agosto do mesmo ano. Logo após a renúncia, os ministros militares que pertenciam à oposição feita ao general Lott procuraram impedir que o vice-presidente João Goulart, que se encontrava no exterior, assumisse a presidência, porém o general Lott divulgou um manifesto conclamando as forças vivas da nação, as forças da produção e do pensamento, os estudantes e os intelectuais, os operários e o povo em geral a tomarem posição em defesa da Constituição.
} 
tempos do ISEB foram difíceis. Sem sede e sem estrutura, os primeiros cursos do ISEB foram ministrados, em 1956, no auditório do Ministério da Educação e Cultura, onde Nelson Werneck Sodré realizou seu primeiro curso de Formação Histórica do Brasil, tendo participado do ISEB desde a sua fundação.

Quando se desencadeou a tempestuosa campanha para a eleição de Kubitschek, alguns desses intelectuais passaram a fornecer-lhe assessoria e formularam sua política do desenvolvimento, na perspectiva das teses econômicas defendidas pela CEPAL. Quando se focaliza essa questão do desenvolvimento brasileiro raramente se leva em conta que ela se concretizou ao longo de um processo atravessado por contradições, conflitos entre diferentes propostas e lutas entre diferentes visões de mundo. A partir da década de cinquenta, acentuam-se as contradições, acirram-se as oposições e ocorrem divisões entre as várias forças e grupos sociais, como é narrado Nelson Werneck Sodré em seu livro Luta pela Cultura. Pelo relato que ele faz, nesse livro, sobre os acontecimentos relacionados ao suicídio de Vargas e à luta pela eleição de Juscelino Kubitschek percebe-se que as forças políticas e militares já estavam não apenas dividas, mas que já havia uma conspiração em curso que culmina com o golpe de 64. Nelson Werneck Sodré enfrenta essas lutas ao lado dos militares nacionalistas, quando era Diretor do Departamento Cultural do Clube Militar, participando com o General Lott do memorável onze de novembro de 1955, que garantiu a legalidade e a posse do presidente JK.

Esse era o contexto no qual Juscelino Kubitschek assumiu a presidência da República. Após sua posse, as coisas se tornaram mais fáceis para o ISEB, e, em 1957, o instituto passou a funcionar com sede própria, na Rua das Palmeiras 55, em Botafogo, promovendo debates sobre os problemas nacionais nas áreas de filosofia, história, a economia, a sociologia, a política e a cultura. O principal objetivo da instituição era inicialmente servir de instrumento para o desenvolvimento de uma ação política na conjuntura econômica e social brasileira, formando quadros para o Estado e para a sociedade brasileira. Para tanto, apresentava-se como um órgão de vanguarda do pensamento desenvolvimentista, reunindo os mais conceituados intelectuais da esquerda, da direita ou do centro ${ }^{10}$.

\footnotetext{
${ }^{10}$ Do qual faziam parte, entre outros: Ignácio Rangel, Miguel Reale, Sérgio Buarque de Holanda, Hélio Jaguaribe, Guerreiro Ramos, Cândido Mendes de Almeida, Cândido Motta Filho, Josué de Castro, Álvaro Vieira Pinto e Nelson Werneck Sodré, sob a direção do filósofo paulista Roland Cavalcanti de Albuquerque Corbisier.
} 
Foi, portanto, a partir do governo JK (1956-1961) que se articulou a estrutura do ISEB, tendo sido composta por um Conselho Consultivo ${ }^{11}$, um Conselho Curador ${ }^{12}$ e por vários Departamentos ${ }^{13}$ Em sua primeira etapa, o ISEB se projeta como uma grande frente intelectual e política, reunindo intelectuais de posições teóricas diversas, mas afinados com as propostas de desenvolvimento e industrialização do país, particularmente com as que foram lançadas no governo JK. Esta frente abarcava diferentes intelectuais e projetos das mais distintas orientações: desde os nacionalistas, socialistas e liberais progressistas até os defensores do capital estrangeiro, como o economista Roberto Campos.

Nelson Werneck Sodré comenta que a heterogeneidade de seus membros ${ }^{14}$, que podia ser muito interessante para uma reflexão sobre os problemas brasileiros dificultava, entretanto, congregá-los para qualquer formulação econômica, política ou social comum. O pensamento da direção, naquela fase pelo menos, era o de formular a ideologia do desenvolvimento. Salienta nosso historiador

\footnotetext{
${ }^{11}$ Este era formado por uma grande variedade de figuras de destaque Abgar Renault, Afrânio Coutinho, Alberto Guerreiro Ramos, Álvaro Lins, Álvaro Vieira Pinto, Ari Torres, Atílio Vivaqua, Cassiano Ricardo, Augusto Frederico Schmidt, padre Augusto Magne, Cândido Mota Filho, Carlos Chagas Filho, Celso Kelly, Djacir Menezes, Fernando de Azevedo, Flaminio Fávero, Francisco Clementino Sant Tiago Dantas, Gilberto Freyre, Heitor Vila Lobos, Herbert Moses, Hermes Lima, Horácio Lafer, João de Scantimburgo, José Carlos Pereira de Sousa, José Flexa Ribeiro, José Honório Rodrigues, José Leite Lopes, Leopoldo Aires, Levi Carneiro, Lucas Lopes, Luís Simões Lopes, Luiz Viana Filho, Marcos Almir Madeira, Mário Travassos, Miguel Reale, Nelson Omegna, Nestor Duarte, Orlando Magalhães Carvalho, Otávio Monteiro de Camargo, Paulo Berredo Carneiro, Paulo Duarte, Pedro Calmon Muniz de Bittencourt, padre Pedro Veloso, Plínio Sussekind Rocha, Sérgio Buarque de Holanda e Sérgio Milliet.

12 Este conselho era composto, inicialmente, pelas seguintes pessoas: Adroaldo Junqueira Aires, Anísio Teixeira, Ernesto Luís de Oliveira Júnior, Helio de Burgos Cabal, Helio Jaguaribe, Roberto de Oliveira Campos, Roland Cavalcanti de Albuquerque Corbisier e Temistocles Brandão Cavalcanti.

${ }^{13}$ Os chefes deles eram os antigos membros do IBESP, acrescidos de mais um novo elemento, o professor Álvaro Vieira Pinto, catedrático de Filosofia da Faculdade de Filosofia, Ciências e Letras da Universidade do Brasil. Ele dirigia o departamento de Filosofia; Cândido Antônio Mendes de Almeida, o de História; Helio Jaguaribe Gomes de Matos, o de Ciência Política; Alberto Guerreiro Ramos, o de Sociologia; e Ewaldo Correia Lima, o de Economia, sendo seu mais destacado colaborador Ignácio Rangel. Nelson Werneck Sodré ficou encarregado de ensinar História Brasileira.

${ }^{14}$ Nelson Werneck Sodré comenta que a composição ampla e heterogênea do início do ISEB refletia o desejo do chamado Grupo de Itatiaia de realizar a mobilização da intelligentzia brasileira, ou daquilo que se supunha ser isso, para, sob sua direção, formular um pensamento político, a que, na falta de melhor nome, batizou-se então de "ideologia do desenvolvimento".
} 
que a proposta era a de que o ISEB elaborasse a "ideologia do desenvolvimento" ou teorizasse sobre o desenvolvimento, enquanto o Presidente Kubitschek a concretizava. Nelson Werneck Sodré critica esta proposta por considerar que isto identificava a instituição, que se pretendia científica, com algo eminentemente circunstancial e vago, na suposição de que uma ideologia poderia ser formulada, assim como um programa, como ato de vontade ${ }^{15}$.

Cresce, então, a importância das forças que combatem pelo desenvolvimento nacionalista e popular, que já vinham tomando impulso a partir da criação, em 1956, de uma Frente Parlamentar Nacional pela defesa da Petrobrás. Nas eleições de 1961, esse movimento nacional popular apóia a candidatura do General Lott. Embora perdendo a eleição, este eminente nacionalista continua sua luta pelo desenvolvimento e pela legalidade, evitando, após a renúncia do presidente Jânio Quadros, a tentativa para impedir a posse de Jango Goulart. O quadro das mudanças sociais em curso $^{16}$, nesse período, havia favorecido a mobilização e radicalização em torno de propostas nacionalistas e antiimperialistas, que, nos anos sessenta, tomam a forma das chamadas reformas de base. O acirramento dessas lutas levará posteriormente ao golpe de 64, no qual a visão nacionalista e popular do desenvolvimento é derrotada, vencendo o grupo que implantará o projeto de desenvolvimento neoliberal, no Brasil.

\section{Adimensão política e cultural da segunda fase do ISEB}

Nelson Werneck Sodré opunha-se à proposta de desenvolvimento do governo do Presidente Kubitschek, considerando que seu Programa de Metas mostrava que ele apenas pretendia acelerar o ritmo de crescimento econômico,

\footnotetext{
${ }^{15}$ Considerava que, por melhores que fossem as intenções, essa proposta limitava o trabalho científico e admitia para a instituição uma finalidade imediatista e partidária.
${ }^{16}$ As transformações sociais desse período haviam conduzido a uma profunda e radical mudança na formação da sociedade brasileira. O processo de industrialização do país e o crescimento da população urbana tornam a vida mais complexa e diversificada, fortalecendo os sindicatos, os par- tidos políticos e os movimentos sociais, conduzindo a um acirramento das contradições e conflitos sociais.


sem tocar na estrutura, de sorte a alcançar determinados níveis meramente quantitativos, particularmente pelo ingresso maciço de capitais estrangeiros. Considerando que esses níveis - ou metas - não passavam de índices de crescimento ou medida dos diversos setores da produção, concluía que, em essência, tratava-se apenas de acelerar o crescimento da economia brasileira pela generalização e aprofundamento das relações capitalistas, segundo um projeto que conciliava essa aceleração com os interesses do imperialismo e mantinha a velha estrutura agrária.

Assim sendo, ocorreu que, ao começar a ser posto em prática, o Plano de Metas provocou uma inevitável cisão no cenário político: de um lado ficaram os partidários do desenvolvimento proposto pelo governo que abria o caminho para o que viria a ser a globalização; enquanto que, do outro lado, ficaram os partidários do desenvolvimento nacionalista, com base numa outra visão da mundialização. Esta cisão se refletiu no ISEB, levando posteriormente à eclosão de sua composição. Em seu livro Luta pela Cultura, Nelson Werneck Sodré descreve detalhadamente a campanha publicitária que alimentou esta cisão e as forças internas e externas que agiram no sentido de levar a uma ruptura final dessa instituição. Apesar de muitas das formulações do ISEB se aglutinarem em torno de uma tese central que ficou conhecida como nacionalismo desenvolvimentista, que parecia se contrapor ao tipo de internacionalização da economia promovida por JK, importantes membros do Instituto apoiaram essa estratégia do presidente.

Parece-me, contudo, incorreto classificar o pensamento de Nelson Werneck Sodré dentro da linha nacional desenvolvimentista, pois ele a ela se opunha. Afinados com a política desenvolvimentista de JK, alguns intelectuais do ISEB receberam apoio do presidente que, em declarações públicas, prestigiou a instituição, definindo-a, como um centro de estudos e pesquisas, que se diferenciava dos demais órgãos universitários por estar voltado para o estudo dos problemas brasileiros. Entretanto, JK criou o Conselho de Desenvolvimento exatamente com essa tarefa e a ele não pertencia nenhum membro do ISEB, o que demonstra um processo de divisão ideológica já em curso, no qual Nelson Werneck Sodré se separa nitidamente das teses do nacionalismo desenvolvimentista de $\mathrm{JK}$ optando por um nacionalismo de raízes culturais e populares. 
A luta de Nelson Werneck Sodré pelo desenvolvimento tem como base sua luta pela cultura ${ }^{17}$, como demonstra o título do livro que estamos comentando. Ao fazer o relato dessas lutas, o autor traça um interessante quadro da dinâmica cultural brasileira, ressaltando a importância do trabalho intelectual e da cultura dentro do processo histórico. Conta que, nessa época, a intelectualidade se fracionou de forma tão violenta, que muitas das feridas então abertas jamais cicatrizaram $^{18}$. Em uma entrevista para o periódico Para Todos ${ }^{19}$, Nelson Werneck Sodré enfatiza que nessa fase se apresentavam, pela primeira vez em nossa história, as condições para o desenvolvimento de uma literatura nacional com base na cultura nacional, na democracia e na integração de enormes parcelas da população na vida nacional ${ }^{20}$.

O conflito entre essas duas perspectivas do desenvolvimento terá uma grande repercussão na vida do ISEB. De um lado, se encontravam os que defendiam as teses de JK e sua proposta de aliança entre a burguesia brasileira e o capitalismo internacional; enquanto que, do outro lado, estava o grupo do qual participava Nelson Werneck Sodré e que defendia um nacionalismo de base popular, que pretendia também atrair a burguesia brasileira e a ela se associar. Ao longo de sua existência, podemos, portanto, distinguir dois momentos na vida do ISEB. O primeiro (1955-1959) foi o de sua criação, que coincidiu com o período desenvolvimentista do governo JK, no qual se iniciou a grande virada do

\footnotetext{
${ }^{17}$ Esta luta implicou o ônus da perda de cargos, de exclusão ou exílio dos centros culturais, de prisão e perda dos direitos políticos. Essa luta correspondeu sempre a uma sobrecarga de trabalho pela intensa participação em várias atividades culturais, em particular em revistas e grandes jornais da época, como a Última Hora e o Correio Paulistano, e em outros meios culturais, como a Associação Brasileira de Escritores (ABDE).

${ }^{18}$ Ele mostra como, no início da década de cinquenta, os escritores estavam divididos, ferozmente divididos, e a ABDE (Associação Brasileira de Escritores) atravessava uma crise terrível, que levou ao afastamento de grande parte dos escritores pelo trabalho de divisão e esforço para esmagar a esquerda, que timbrava em querer que a ABDE militasse de fato em defesa da liberdade gravemente ferida no Brasil e pelo sectarismo e isolamento dos esquerdistas.
}

${ }^{19}$ Este periódico, que tinha ressurgido em 1956 sob a direção de Jorge Amado, organizou, no segundo semestre de 1957, um inquérito importante com uma série de intelectuais sobre o panorama da cultura brasileira, naquela fase do nosso desenvolvimento histórico e social, no qual se integra essa entrevista.

${ }^{20}$ Em suas aulas, em seus artigos e suas notas de crítica ou em suas conferências, como as que ele pronunciou, no Clube de Engenharia, em 22 de maio de 1957, defendia sempre a cultura nacional e uma literatura para servir ao povo, sem injunções colonialistas. 
capitalismo brasileiro, favorecendo a entrada de tecnologia e capital estrangeiro. Nessa fase, um grupo de intelectuais do ISEB adere à proposta de JK, enquanto o outro grupo aprofunda sua crítica desse caminho do desenvolvimento. Em 1958, essas oposições de pontos de vista levam a uma crise interna que divide o ISEB, dando início a uma nova fase na qual as críticas às teses desenvolvimentistas se acentuam.

Decorridos cinco anos do governo do governo JK, a realidade indicava que o país crescera economicamente, com a consolidação do capitalismo industrial, mas não tinha resolvido seus problemas sociais e as desigualdades tinham aumentado. Nessa segunda fase, ocorreu uma maior politização e a harmonia de idéias sobre o desenvolvimento sofreu fissuras, levando a uma crise dentro do ISEB que provocou uma cisão considerada por Nelson Werneck Sodré como inoportuna, inadequada e sectária. Tendo crescido a oposição entre o grupo liderado por Hélio Jaguaribe e a corrente da qual faziam parte Roland Corbisier e Alberto Guerreiro Ramos, favorável a uma ação menos acadêmica e mais engajada, aquele eminente idealizador do ISEB acabou deixando o instituto, tendo sua saída sido posteriormente profundamente lamentada por Nelson Werneck Sodré. Nova crise leva à saída de Guerreiro Ramos, após a qual o instituto passa a ser dirigido pelos professores Vieira Pinto e Roland Corbisier, que, apoiados por Nelson Werneck Sodré, acompanham o movimento de radicalização do país, privilegiando as mudanças econômico-sociais e as reformas de base defendidas pelo governo João Goulart. Sob a orientação desses três intelectuais, o ISEB, nessa segunda fase de sua história, assume uma posição mais agressiva na crítica dos lucros das empresas estrangeiras, da remessa de lucros, da distribuição de renda e da transformação da estrutura agrária.

Após essas crises, o ISEB reformulou suas atividades, ampliando seus cursos, até então dirigido a alunos indicados pelo serviço público, a exemplo do que já fizera a Fundação Getúlio Vargas. A meta agora era atingir um público maior. Tendo em vista esse objetivo, o ISEB passou a oferecer cursos regulares a militares, estudantes, sindicalistas, empresários, parlamentares, artistas, profissionais liberais, etc. Passou a produzir, também, pequenos livros, denominados Cadernos do Povo, que eram feitos numa linguagem acessível e didaticamente elaborados para serem dirigidos às camadas menos privilegiadas e às classes trabalhadoras. Foi nesse momento, a partir dos anos sessenta, que se intensifica 
a atividade intelectual e cultural em torno do ISEB, passando este a exercer uma grande influência e a impregnar a esfera cultural, difundindo uma forma de pensamento e de cultura marcada pela defesa do nacional e do popular.

Essa nova forma de pensamento cultural em defesa do nacional e do popular está nas raízes das propostas do Centro Popular de Cultura (CPC) ligado à União Nacional dos Estudantes (UNE), que era animado por artistas e intelectuais estreitamente relacionados ao ISEB e à Revista Civilização Brasileira. Esse enfoque com base na cultura nacional e popular já vinha sendo tecida por Nelson Werneck Sodré há vários anos, a partir de suas concepções e de um intenso intercâmbio com vários artistas e intelectuais de diversas áreas que frequentavam sua casa, mas ela toma forma com o movimento que se aglutina em torno do CPC da UNE, criado em 1961, com a proposta de construção de uma cultura popular e democrática.

Desse modo, na segunda fase de sua história, o ISEB constrói uma ponte ligando os intelectuais, os artistas e os representantes das diferentes áreas da cultura com os estudantes por intermédio do CPC. Nesse período, eu participava como estudante do ISEB e da UNE e acompanhava de perto essas articulações. Não havia nenhuma vinculação entre o ISEB e o CPC, como muitas vezes se sugere. $\mathrm{O}$ que existiu foi a convivência e troca de idéias entre pessoas que integravam estas duas instituições e costumavam se frequentar mutuamente. Participei pessoalmente intensamente da atividade dessas duas instituições e me embebi das idéias que circulavam em ambas, tendo observado, contudo, que essas duas instituições que me eram tão caras mantinham suas vidas e atividades separadas sem que houvesse nenhuma forma de associação entre seus membros.

O elemento de ligação entre o ISEB e a UNE era um sociólogo do ISEB, Carlos Estevão Martins, que foi o criador e primeiro diretor do CPC. Ele era ligado ao grupo paulista do Teatro de Arena, que se instalou posteriormente também no Rio de Janeiro ${ }^{21}$. Entre 1961 e 1964, o CPC produziu dezenas de peças e shows musicais, com o apoio do ISEB e a colaboração de muitos artistas, poetas,

\footnotetext{
${ }^{21}$ Os representantes desse grupo teatral realizaram peças políticas de grande sucesso, entre elas: Eles não usam black tie, de Gianfrancesco Guarnieri; Chapetuba Futebol Clube, de Oduvaldo Vianna Filho; e A mais-valia vai acabar, seu Edgard, de Oduvaldo Vianna Filho e Francisco de Assis, musicado por Carlos Lyra, que analisava didaticamente o conceito ideológico da teoria marxista.
} 
escritores e atores, Essas peças e shows foram apresentados em diversos teatros, universidades, locais de trabalho e feiras de livros. O CPC percorreu o Brasil de norte a sul, tendo criado centros culturais semelhantes em outros estados, como o Movimento de Cultura Popular do Recife, do qual participou Nelson Xavier. No Rio, nós tínhamos um grupo de redação de textos teatrais, na UNE, dirigido por Oduvaldo Vianna Filho, do qual eu fazia parte. A parceria do ISEB com a UNE teve também influência nas edições dos Cadernos Brasileiros e na História Nova dirigida por Nelson Werneck Sodré.

O grupo que realizou o golpe de estado de 1964 devia considerar as atividades dessas instituições como muito perigosas, pois, logo ao chegar ao poder, se apressou em desmantelar a UNE, o ISEB e o CPC, fechando e arrasando suas sedes. Imediatamente após a instalação da ditadura, em 31 de março de 1964, o ISEB foi extinto por decreto, tendo sido seus diretores e professores investigados e Nelson Werneck Sodré preso. Posteriormente foi instaurado até mesmo um inquérito policial-militar (IPM) para apurar as atividades do Instituto, durante o qual Nelson Werneck Sodré deu um extraordinário depoimento em defesa de suas idéias e propostas sobre o desenvolvimento do Brasil e a cultura nacional e popular, que já se tornaram objeto de pesquisa e tese de doutorado. 